\title{
SAUdAÇÃO PROFERIDA PELO PROFESSOR CELSO LAFER AO NOVO TITULAR, PROFESSOR ALCIDES JORGE COSTA
}

É uma honra e uma alegria saudar o Professor Alcides Jorge Costa em nome de seus colegas da Congregação, por ocasião desta sua posse solene como Professor Titular de Direito Tributário. Esta saudação, no entanto, não está na ordem natural das coisas; é fruto das circunstâncias, do tempo e das conjunturas dos concursos. Com efeito, Alcides é meu senior. Comecei a trabalhar com ele; ele teve um papel na minha formação, como explicitei no meu discurso de posse, qualificando-o como "o amigo mais velho que foi me ajudando intelectualmente a separar o joio do trigo com o discernimento de sua límpida inteligência e o seu sempre pertinente saber" Ele continua, como todos sabem, sendo este Amigo. Não tenho, portanto, a autorictas para saudá-lo. Entretanto, mais de trinta anos de diálogo constante, praticamente diário pessoal, intelectual, profissional - tornamme apto a dar um depoimento e esboçar o seu perfil e é isto que tentarei, a seguir, fazer.

O Professor Alcides Jorge Costa é uma das mais límpidas inteligências que conheci. Esta inteligência é admiravelmente bem servida; em primeiro lugar por uma cultura sólida e muito bem organizada - reveladora do leitor que ele foi, desde jovem, do Discurso sobre o Método, de Descartes e que domina, com segurança, o campo do Direito. Esta inteligência tem o lastro do senso crítico, condimentado por humor e é auxiliada pelo humanismo de quem também se formou em letras clássicas e foi professor-assistente de língua e literatura latina na Faculdade de Filosofia, Ciências e Letras da USP É igualmente instrumentada pelo conhecimento da História e das Ciências Sociais, com uma passagem acadêmica nesta área como professor-assistente de Ciência das Finanças, na Faculdade de 
Economia e Administração da USP, disciplina que, na época, tinha como catedrático o Professor Theotonio Monteiro de Barros.

Finalmente, é uma inteligência temperada pela experiência e aqui vejo a herança portuguesa - sobre a qual tantas vezes falamos e evoco Duarte Pacheco Pereira que, no Esmeraldo de Situ Orbis, diz "ha experiencia que he madre das cousas nos desengana e de toda dúvida nos tira" - recordando o que Sérgio Buarque de Holanda, ao comentar este texto, observou: "madre das coisas, não apenas sua mestra, de acordo com a fórmula antiga" A experiência, como "madre das cousas" em Alcides aguça a percepção do concreto, fazendo com que, no trato das coisas, ele vá com argúcia sempre ao ponto, sem se perder em atalhos ou escorregar em abstrações.

Como é que isto tudo se articula na sua trajetória? Começo pela produção intelectual, observando, preliminarmente, que o Direito pode ser examinado a partir do ângulo interno do sistema jurídico, da norma dentro do ordenamento, o que leva a uma Teoria Geral do Direito rigorosa na busca da conexão coerente entre as normas, na sua estática e na sua dinâmica. O Direito também pode ser a partir do ângulo externo, ou seja, discutindo-se as relações entre $o$ interno do sistema jurídico e o externo que o abrange e circunscreve.

A contribuição de Alcides a partir do ângulo interno, no campo do Direito Tributário, tem como nota identificadora a clareza e o rigor conceitual iluminado por uma visão geral de quem navega com tranqüilidade pela Teoria Geral do Direito. A sua tese de doutoramento de 1972, Contribuição ao Estudo da Obrigação Tributária, tem como cerne a aplicação da teoria dualista das obrigações à obrigação tributária, e a sua tese de titularidade de 1991, Da Extinção das Obrigações Tributárias, cuida de tema de relevo, pouco explorado na literatura brasileira. Ambas, em função da importância do conceito de obrigação para a Teoria Geral do Direito, são importantes para inserir racional e metodicamente o Direito Tributário no universo jurídico.

Nesta mesma linha cartesiana, cabe mencionar o seu texto Direito Tributário e Direito Privado, publicado nos estudos em homenagem ao Professor Ruy Barbosa Nogueira, seu grande incentivador, amigo e eminente antecessor, que 
aqui menciono com o maior apreço pessoal e intelectual. Nele cuida das analogias entre Direito Público e Direito Privado, tema importante da epistemologia jurídica, em função da relevância da dicotomia para a Teoria Geral do Direito. Quero, igualmente, fazer referência ao seu trabalho sobre $A$ Doutrina Tributária Italiana $e$ sua Influência no Direito Tributário Brasileiro, inserido nos estudos em homenagem a Gilberto de Ulhôa Canto, no qual examina outro tema de importância da epistemologia jurídica: a doutrina como inspiradora do direito positivo, seja em termos de criação, seja em termos de aplicação da norma. Menciono, ainda, o Natureza Jurídica dos Empréstimos Compulsórios, artigo de 1962, que marcou época e influenciou a jurisprudência ao mostrar o papel dos conceitos na dogmática analítica, na dogmática hermenêutica e na dogmática da decisão, para recorrer à tipologia do Professor Tércio Sampaio Ferraz Jr. Em síntese, a partir do ângulo interno, vejo Alcides como continuador de Rubens Gomes de Souza, seu amigo e companheiro de escritório, o eminente consolidador teórico e codificador do Direito Tributário em nosso país.

Na produção intelectual de Alcides está presente, também, uma aguda percepção da relação entre o interno do sistema jurídico e o externo que o abrange e circunscreve. Aqui vejo o impacto da liçâo de Tullio Ascarelli, com quem teve muitos contatos de trabalho no início de sua vida profissional e que sempre levava em conta, na sua elaboração jurídica, a realidade sócio-político-econômica.

Começo citando um artigo de 1962, que foi, aliás, o primeiro artigo dele que li, quando estava no terceiro ano da Faculdade: Imposto de Vendas $e$ Consignações: Análise dos Sistemas de Arrecadação. Neste texto discutia, com conhecimentos teóricos de finanças aguçados pela percepção da realidade brasileira, em que estágio do ciclo econômico devia incidir o imposto de vendas e por que? Menciono também a sua bela tese de livre-docência de 1977, ICM na Constituição era Lei Complementar, que é trabalho de cunho jurídico, com as necessárias referências a aspectos econômicos e políticos dados pelo foco preciso de sua experiência profissional e que são imprescindíveis a melhor compreensão dos princípios do imposto. Não quero deixar de me referir ao recente curso de pósgraduação sobre federalismo tributário, inspirado pelo desejo de iluminar, com senso crítico, a interação entre doutrina, normas, princípios e realidades.

Faço estas menções com o objetivo de realçar a importância da complementaridade entre ângulo interno e externo para o Direito Tributário, que é a disciplina da qual Alcides é o novo titular. É com base nesta complementaridade 
que Alcides sabe fazer a crítica dos pressupostos, ou seja, pensar o significado do conhecimento do Direito Positivo, que é, a meu ver, a tarefa da Filosofia do Direito. Vou dar dois grandes exemplos dessa sua capacidade de lidar com a dicotomia pensar/conhecer.

O primeiro é a estupenda prova de erudição no concurso para Professor Titular, na qual examinou a relação jurídica tributária na doutrina, rastreando as concepções do Direito e as realidades inerentes à interação, no tempo, entre o exercício do poder do Estado e o contribuinte. Conheço poucos tratamentos tão competentes quanto este sobre a temática, sempre atual e difícil, da relação Direito e Poder. O segundo é a admirável aula inaugural deste ano na qual abordou, com visão histórica, o tema da reforma tributária no Brasil e que teve como tema substantivo as discrepâncias entre a teoria e as realidades sócio-político-econômicas do nosso país.

A produção intelectual de Alcides, na forma de publicações doutrinárias, é muito menor do que poderia ser. A razão, a meu ver, é excesso de senso crítico em relação a si mesmo e excesso de generosidade em relação aos outros, generosidade que se traduz na sua dimensão pública, na prestação de serviços à comunidade.

\section{IV}

A prestação de serviços à comunidade, de Alcides, está basicamente ligada à disciplina da qual é hoje o Professor Titular: Direito Tributário, e a sua capacidade de lidar com a dicotomia pensar o significado/conhecer tecnicamente o Direito e suas implicações práticas, que acabo de examinar. Explico-me. No mundo contemporâneo, o exercício do poder e ação política requerem a contribuição dos intelectuais. Esta contribuição desdobra-se, para efeitos analíticos, como observa Bobbio - em Il Dubbio e la Scelta entre intelectuais que produzem e transmitem princípios-diretivos conhecimentos-fim, que são os ideólogos, e os que produzem e transmitem conhecimentos-meio - soluções técnicas, que são os experts. Nosso caro Alcides, em função de seu senso crítico, sabe lidar com os princípios-diretivos e, por obra de seu saber técnico, é capaz de oferecer soluções para desatar os nós do sistema tributário brasileiro. Daí a sua inestimável contribuição à res publica, pois vem colocando o seu saber técnico consciente, sempre graciosamente, a serviço da 
União, dos Estados e dos municípios; do Legislativo e do Executivo, colaborando, com inteligência e objetividade, para o bem comum.

Este tem sido o seu papel durante décadas, em importantes mudanças da legislação tributária brasileira. Destaco, inter alia, seu trabalho na revisão do Código Tributário Nacional, na implantação do ICM no Estado de São Paulo, no assessoramento à constituinte de 1988 e em múltiplas comissões formais e informais de reformas tributárias no âmbito Federal, do Estado e do Município de São Paulo.

Esta sua prestação de serviços à comunidade caracteriza-se, por ser "austera como convém à República e discreta como é do gosto dos mineiros", para recorrer a uma frase de Milton Campos que muito se ajusta à personalidade de Alcides Jorge Costa.

\section{V}

As características de Alcides Jorge Costa, acima apontadas, confluem todas para dele fazer, sem alarde, um grande Professor.

São notas identificadoras de Alcides, como professor, além da clareza e do rigor de um sólido conhecimento e do interesse generoso pelos alunos, que anima sua vocação pedagógica, a responsabilidade e a seriedade. Estas virtudes se traduzem no preparo do cursos e das aulas e na orientação de alunos e, no âmbito mais amplo da Faculdade, no zelo inovador com o qual vem presidindo a Comissão da Biblioteca.

Para concluir: estamos vivendo, no Brasil e no mundo, uma demanda generalizada de Ética. Direito e Ética são conjuntos normativos que têm uma dupla aspiração: (i) a de modelação do comportamento humano; (ii) a de um juizo crítico sobre o comportamento humano; crítico no sentido de censurar mas também no de justificar.

Como conjuntos normativos - Ética e Política pretendem realizar uma mediação entre fatos e valores consagrados nas normas. Esta mediação gera, 
por sua vez, uma dupla tensão, como aponta Ruiz Miguel: (i) a de propor modelos inúteis porque irrealizáveis - é a utopia, que se caracteriza pelo hiato entre práticas efetivas e as desejadas ou desejáveis; (ii) a de sucumbir diante da realidade, sem pretender orientá-la são os perigos do realismo, da aceitação inquestionada dos fatos.

O Professor Alcides Jorge Costa, por ser um espírito independente (e, aliás, por esse motivo sempre prezou a sua condição de profissional liberal), exerce constantemente o seu juízo crítico e, por isso, não incide, nem nos riscos da utopia, nem nos perigos do realismo, na sua atitude diante do mundo e na sua vida profissional e intelectual. Não incide também porque, sem falsos moralismos, é um homem de virtudes. É uma pessoa de caráter. Na sua maneira de ser estão presentes as virtudes clássicas, que os gregos analisaram - a coragem, a temperança, a sabedoria, a justiça - discretamente sustentadas pelas virtudes teológicas da fé, da esperança e da caridade. Por isso, na sua sóbria figura, encontramos os seus amigos, colegas e alunos - um paradigma de pessoa que suscita a melhor admiração. 